BULLETIN Bulletin hispanique

HISPANIQUE Université Michel de Montaigne Bordeaux

118-1 | 2016

La Guerre Civile espagnole aujourd'hui (1936-2016)

\title{
La Italia española de un poeta de Sevilla
}

en torno a una nueva edición de Gutierre de Cetina (1520-c.1554)

\section{Mercedes Blanco}

\section{(2) OpenEdition}

Journals

Edición electrónica

URL: http://journals.openedition.org/bulletinhispanique/4342

DOI: 10.4000/bulletinhispanique.4342

ISSN: $1775-3821$

Editor

Presses universitaires de Bordeaux

Edición impresa

Fecha de publicación: 15 julio 2016

Paginación: 253-274

ISBN: 979-10-300-0058-0

ISSN: 0007-4640

Referencia electrónica

Mercedes Blanco, «La Italia española de un poeta de Sevilla », Bulletin hispanique [En línea],

118-1 | 2016, Publicado el 15 julio 2019, consultado el 06 septiembre 2019. URL : http://

journals.openedition.org/bulletinhispanique/4342; DOI : 10.4000/bulletinhispanique.4342 


\title{
La Italia española de un poeta de Sevilla: en torno a una nueva edición de Gutierre de Cetina (1520-c.1554) ${ }^{1}$
}

\author{
Mercedes Blanco \\ Université de Paris Sorbonne - Paris IV
}

Lédition des Rimas du poète sévillan Gutierre de Cetina par Jesús Ponce Cárdenas nous livre un panorama très riche de sa culture, son monde social, son esthétique et son influence. Cetina séjourna en Italie en 1538-1548, au moment où se formait un champ littéraire italien basé sur le toscan et sur le pétrarquisme théorisé par Bembo et diffusé par les anthologies publiées par Giolito. Ce contexte eut une influence décisive sur la poésie du Sévillan, homme à la culture vernaculaire et moderne, et, indirectement, sur toute la poésie du Siècle d'or.

Mots-clés : Cetina, pétrarquisme, poésie italianisante, imitation, canzoniere, Séville à la Renaissance.

La edición por Jesús Ponce Cárdenas de las Rimas de Gutierre de Cetina, aporta un detallado panorama de su cultura, su mundo, sus técnicas retóricas y poéticas y su influjo. La coincidencia temporal de la estancia de Cetina en Italia (1538-1548) y de la consolidación de un campo literario italiano basado en el idioma toscano y en el petrarquismo teorizado por Bembo y difundido por las antologías, influyó decisivamente en la poesía del sevillano, y por mediación de esta, en los géneros poéticos del siglo de Oro.

Palabras-claves: Cetina, petrarquismo, imitación, Tansillo en España, cancionero, Renacimiento sevillano.

With the new edition of Seville poet Gutierre de Cetina’s "Rimas", due to Jesús Ponce Cárdenas, we are in possession of a updated and comprehensive overview of Cetina's culture, social world, aesthetics, and influence on subsequent generations. Cetina stayed in Italy from 1538 to 1548 , precisely while an Italian literary field was being formed, based on Tuscan and on the particular kind of Petrarchism, theorized by Bembo, and broadcast by the anthologies published by Giolito in Venice. The fact had a decisive influence on the Sevillian poet whose culture was essentially vernacular and modern, and on Spanish Early Modern poetry.

Keywords: Cetina, Petrarchism, Italianate poetry, imitation, canzoniere, Renaissance Seville.

1. Gutierre de Cetina, Rimas, ed. Jesús Ponce Cárdenas, Madrid, Cátedra, 2014, 1238 p.

Bulletin Hispanique, Tome 118, n 1 - juin 2016 - p. 253-274. 
Tesús Ponce Cárdenas ya había demostrado, en sus ediciones de Francisco de Medrano y Anastasio Pantaleón de Ribera, y últimamente de la Fábula de Polifemo y Galatea de Góngora (Madrid, Cátedra, 2012), sobresalientes cualidades para la tarea. Colma, con este nuevo trabajo, las expectativas que despiertan los anteriores. Sus Rimas de Gutierre de Cetina (c. 1515-1554 a 1557) arrojan potente luz sobre la personalidad del poeta y dan a leer del modo más grato y provechoso los versos de este sevillano de perfil típicamente renacentista. Como sabíamos ya, y verificamos en esta edición con superiores precisión y nitidez, Cetina representa el momento en que la poesía española absorbe definitivamente mucho de lo que la cultura del Renacimiento había ido depositando en la lengua literaria de Italia ${ }^{2}$. El libro, que sobrepasa las mil doscientas páginas, ha sido realizado por la editorial Cátedra para su colección "Letras hispánicas» con un esmero y liberalidad que la hacen acreedora de la gratitud de los estudiosos y merecen que le auguremos éxito con los lectores.

Como en sus anteriores trabajos editoriales, Jesús Ponce plantea la introducción como una amplia monografía, que no se limita a sintetizar lo ya sabido sino que lo enriquece con hallazgos propios y lo anima con un punto de vista original. Se abre con una concisa y elegante biografía del poeta (pp. 1137), apoyada en la documentación disponible (hallada hace tiempo por Narciso Alonso Cortes ${ }^{3}$, Rafael Lapesa ${ }^{4}$ y Marcel Bataillon ${ }^{5}$, en lo que atañe a Italia, y por Francisco Rodríguez Marín, en lo referente al caso violento sufrido en Méjico en $1554^{6}$ ). Con respecto a la biografía redactada por Begońa López Bueno para su libro de 1978, las pocas novedades documentales permiten caracterizar mejor la parentela de Cetina, con evidencia de un linaje converso por el lado paterno y el materno, de que no parece haber habido sospecha hasta los trabajos de Ruth Pike y de Juan $\mathrm{Gil}^{7}$. Jesús Ponce amplifica el relato basado en esta documentación mediante datos adyacentes, que proceden de investigaciones recientes o propias, y permiten imaginar el entorno social y cultural de Cetina, en las varias fases de su trayectoria: empezando por la

2. La condición renacentista de Cetina fue subrayada ya desde el título, en la única monografía importante de que disponíamos sobre el poeta: Begońa López Bueno, Gutierre de Cetina, poeta del Renacimiento español, Sevilla, Diputación, 1978, un trabajo que, junto con la edición en 1981 de los Sonetos y madrigales completos, por la misma estudiosa, constituyó un paso decisivo hacia el estudio científico del poeta según criterios actuales.

3. Narciso Alonso Cortés, "Datos para la biografía de Cetina», Boletín de la Real Academia Española 32/135 (1952), pp. 73-118.

4. Rafael Lapesa, "Gutierre de Cetina. Disquisiciones biográficas», Estudios hispánicos. homenaje a Archer M. Huntington, Wellesley, Wellesley College, 1952, pp. 311-326.

5. Marcel Bataillon, «Gutierre de Cetina en Italia», Studia hispanica in honorem Rafael Lapesa, Madrid, Gredos, 1972, pp. 153-172.

6. Antonio Rodríguez Marín, «Documentos sobre Gutierre de Cetina», Boletín de la Real Academia Española VI (1919), pp. 54-115.

7. Ruth Pike, "The converso origins of the Sevillian poet Gutierre de Cetina», Iberoromania 32 (1990), pp. 47-54.

8. Juan Gil, Los conversos y la Inquisición sevillana. Ensayo de prosopografía, vol. III, Sevilla, Universidad de Sevilla-Fundación El Monte, 2001, pp. 512-513. 
adolescencia, sobre la cual carecemos de documentos, en pleno auge de Sevilla; y siguiendo por la juventud en que nos topamos a Cetina desempeñando funciones de agente de Francisco Duarte, pariente lejano y sin duda amigo de su padre Beltrán de Cetina. Fue probablemente el hábil Duarte, que pasó de Factor de la Casa de Contratación de Sevilla a "Contador de Cuentas de su Majestad en Italia, y Proveedor y Comisario general de sus armadas y ejércitos», quien lanzó la carrera del joven sevillano al asociarlo a su personal administrativo: en una carta del alto funcionario dirigida al secretario Francisco de los Cobos, fechada en Corfú el 10 de octubre de 1538, que habla de la organización de la defensa de Italia frente a la armada turca, Cetina aparece como encargado de acompañar cuatro naves con bastimentos con rumbo a Otranto, y de llevar cartas de instrucción para las autoridades españolas en Apulia y Nápoles. Pocos meses después nos lo encontramos convertido en criado del brillante Ferrante Gonzaga, virrey de Sicilia de 1535 a 1546 y más tarde gobernador de Lombardía, para quien desempeñará cometidos de correo y portavoz con Carlos $\mathrm{V}$ y con el príncipe Felipe, y a quien acompañará en una victoriosa campaña militar en Alemania, Flandes y Norte de Francia (15431544). Sigue a estos años, que deben esporádica luz documental al paso de Cetina por los centros vitales del Imperio, la estancia en Sevilla (1548-1553), al parecer pobre en acontecimientos, de que se tiene noticia principalmente por la tardía semblanza biográfica del Libro de retratos de Pacheco (1599). Por último, un período de residencia en México, truncado en fecha incierta por la muerte. Esta se debió probablemente a las salvajes cuchichadas sufridas en La Puebla a raíz de un sórdido affaire más o menos sentimental, pese a que en un primer momento el poeta pareció reponerse de sus graves heridas.

Se desprende de la biografía un perfil social bien caracterizado: Cetina perteneció a una familia sevillana de rica burguesía con antepasados conversos por ambas ramas, lo que no le impidió integrarse, como caballero, cortesano y militar, al ambiente de la nobleza hispano-italiana y al servicio directo de la monarquía hispánica en su momento de mayor esplendor. Por alguna razón desconocida, abandonó esa carrera para retirarse a Sevilla y luego para ir a buscar fortuna en México siguiendo un camino ya trazado por su rica familia materna -al amparo de un tío, Gonzalo López, marido de la hermana de su madre y que desempeñaba el cargo de Procurador de la Audiencia mexicana. Sería tentador ver en esta posición ambigua una de las causas de la inestabilidad de su inspiración (que alterna, en contraste con lo que se verificaba en los nobles Boscán y Garcilaso, lo grave y elevado y lo festivo y burlesco) si ésta no se verificara en su contemporáneo Diego Hurtado de Mendoza, miembro de la más alta y opulenta nobleza castellana. Este famoso embajador imperial en Venecia y en Roma tiene afinidades con Cetina, que la edición que reseñamos recalca, marcando los puntos de encuentro entre ambos ingenios: el interés por el epigrama antiguo y neolatino y sus adaptaciones vernáculas (pp. 56-77), el cultivo de las estancias en octavas, predilectas de Hurtado de Mendoza y que también frecuenta Cetina, como observa Ponce por primera vez (p. 67), el capitolo en tercetos de tema amoroso; el encomio paradójico en prosa y en 
verso; la epístola familiar en versos sueltos o en tercetos (pp. 97-106). Ambos comparten el gusto por la pintura ${ }^{9}$ y la admiración por Tiziano (entonces de rigor en círculos cortesanos), y en ambos la lírica amorosa, aunque de signo más puramente petrarquista en Cetina -lo que muy bien podría deberse a los quince ańos que le lleva Hurtado de Mendoza-, coexiste con una vena jocosa y desenfadada, proclive al chiste y al equívoco salaz. De esta proximidad de ambos ingenios son síntoma algunos poemas atribuidos por los códices alternativamente a uno u otro: así los tercetos «A la pulga», y "En alabanza de la cola». Jesús Ponce los edita en estas Rimas (pp. 950-968 y pp. 1024-1049) y basa su atribución a Cetina en las reflexiones de los recientes editores del Cancionero sevillano de Toledo ${ }^{10}$. Sin embargo el atento editor de Hurtado de Mendoza, J. Ignacio Díez Fernández, incluye ambos textos respectivamente entre los de autoría segura de su poeta, y los de atribución compartida ${ }^{11}$.

La cultura de Cetina, contrariamente a la del rico diplomático, debió de ser principalmente vernácula, aunque no ignoró el latín, como parecen indicarlo sus traducciones de tres de las Heroidas de Ovidio (pp. 1151-1201) y el soneto CLII, que se presenta como "traducción de un epigrama latino» y es en efecto adaptación de un epigrama celebérrimo de atribución discutida, "Thrax puer adstricto glacie cum luderet Hebro» (pp. 506-508). Todo ello no sobrepasa mucho, con todo, el nivel de ejercicios escolares. Su Fábula de Amor y Psique, única incursión en el ámbito del «epyllion $»^{12}$, traduce un poema anónimo italiano, la Favola di Psiche. Esta composición de treinta y dos octavas que versifica con gracia el famoso cuento engastado en El asno de oro, sirvió de leyenda a una bellísima serie de 32 grabados, publicados en Roma en 1532 por Antonio Martínez de Salamanca, cuyas buenas reproducciones amenizan estas Rimas (pp. 831-883). La minuciosa comparación que lleva a cabo Jesús Ponce entre los versos del anónimo italiano, el relato en prosa latina que este resume, y la

9. Rimas, p. 134: «No puede olvidarse que, junto con Diego Hurtado de Mendoza, se considera a Cetina el introductor del tema del retrato en la lírica renacentista, ya que en torno al mismo compuso un complejo políptico de cuatro sonetos y una octava epigramática.» Véase también Jesús Ponce Cárdenas, «La octava real y el arte del retrato en el Renacimiento», Criticón, 114, 2012, p. 71-100.

10. Este códice, de cuya importancia para el corpus cetiniano dio noticia José Manuel Blecua, "Poemas menores de Gutierre de Cetina», y "Otros poemas inéditos de Gutierre de Cetina», Sobre poesía de la Edad de Oro (ensayos y notas eruditas), Madrid, Gredos, 1971, pp. 44-61 y 62-73) contiene sesenta y un poemas de Cetina. Véase Cancionero sevillano de Toledo, manuscrito 506 (fondo Borbón-Lorenzana), Biblioteca de Castilla-La Mancha, eds. José J. Labrador, Ralp. DiFranco y Juan Montero, Sevilla, Universidad de Sevilla, 2006, p. 4: «... el libro II está dedicado de manera exclusiva a Gutierre de Cetina. Los 51 poemas que ahí se le adjudican (seis de los cuales se han perdido) constituyen sin duda la sección más valiosa de la colección, y este corpus, enriquecido luego en el libro $\mathrm{V}$ con otros poemas suyos, hace de nuestro códice uno de los más importantes (y el más temprano entre ellos), para el conocimiento de la obra del poeta sevillano, junto con MN 2973 y MRAE ReM 6939.»

11. Diego Hurtado de Mendoza, Poesía completa, ed. J. Ignacio Díaz Fernández, Sevilla, Fundación José Manuel Lara, 2007, pp. 5-13, y pp. 582-593.

12. Se ocupó de este texto anteriormente Francisco Javier Escobar Borrego, El mito de Psique y Cupido en la poesía española del siglo XVI, Sevilla, Universidad de Sevilla, 2002, pp. 77-169. 
traducción de Cetina, permite ver que en ningún momento el poeta castellano procuró enriquecer su versión interpolando algún detalle directamente tomado del soberbio texto de Apuleyo. Al contrario, elimina expresiones características del escritor latino que sí había retenido el autor de la Favola di Psiche. Como observa Ponce, en "seis de las treinta y dos estrofas», Cetina incorpora en cambio algún tipo de fórmula «que exhorta a la fruición visual, dirigiendo la mirada hacia algún elemento de la imago» (p. 132), con expresiones como "Vesla aquí», «Vesla allá», "Mira cómo», "Allí aparece». Todo ello sugiere que Cetina escribió teniendo delante la serie de grabados con sus octavas italianas al pie, y desde luego no se preocupó de abrir El asno de oro, indicio del carácter moderno, cortesano y vernáculo de sus hábitos como lector y escritor.

El texto de Rimas está basado, suponemos, en el cotejo de los diferentes códices en que aparece la poesía de Cetina, de los cuales el más importante es el Ms RAE-RM 6939, único que le está dedicado en exclusiva y que «se estima copia temprana de un códice autógrafo». Además de otros tres cartapacios que contienen un grupo más o menos nutrido de composiciones de nuestro poeta, algunas copias de poesías aisladas aparecen en cancioneros de varios autores, de que hace recuento José Manuel Rico en una contribución calificada de "capital» por Jesús Ponce ${ }^{13}$. La edición que este lleva a cabo, tal vez por imperativos editoriales, carece de aparato crítico, y no suele indicar la procedencia de los textos. Estos se presentan modernizados, según normas no precisadas que son las habituales en la colección.

La anotación, aspecto altamente encomiable de la labor editorial de Jesús Ponce que ya había podido apreciarse en la Fábula de Polifemo de Góngora, se concibe como el acopio de todos los datos que se han podido rastrear para aclarar cada poema y sus circunstancias y pone a disposición del lector la tradición literaria sobre cuyo fondo el texto recupera todo su sentido y cobra máximo relieve. Lo cual implica una erudita y sutil paráfrasis de aquellos pasajes que se resisten a la inmediata inteligencia; así como la cita integral, en sus idiomas originales, de los textos imitados por Cetina que, salvo casos particulares (la poesía de Ausias March, las Heroidas de Ovidio), son siempre italianos. De estos poetas mayores o menores, pero siempre diestros y cultos, Cetina escoge, salvo en los casos de Petrarca y Tansillo, un corto número de textos, a menudo uno solo. Suele tratarse de sonetos populares entre los literatos, valga el oxímoron, y cuya imitación por muchos (a veces casi pura traducción, a veces reelaboración más o menos libre) viene a ser homenaje al logro memorable de un poeta, ya sea éste célebre o casi desconocido ${ }^{14}$. Cuando

13. Gutierre de Cetina, en VV. AA, Diccionario filológico de literatura española. Siglo XVI, Madrid, Castalia, 2009, pp. 241-50.

14. Así sucede por ejemplo con el bello soneto de un poeta de escaso renombre, Giovanni Mozzarelli, que compara la crueldad de su dama con la de Nerón mirando el incendio de Roma, Mentre i superbi tetti a parte a parte. Este texto, popularizado a partir de su impresión en la famosa antología Rime diverse (Venecia, Giolito, 1545), fue adaptado por Cetina en «Mientra con gran terror por cada parte» y por Hernando de Acuña entre "Mientra de parte en parte se abrasaba» (J.P. Wickersham Crawford, «Two Spanish Imitations of an Italian Sonnet», Modern Language 
el poema de Cetina no sigue, que sepamos, ningún modelo, la anotación de Jesús Ponce, por lo general más extensa que el texto mismo, señala los motivos que vertebran la composición, ya sean comparaciones, alegorías u otras figuras, referencias mitológicas, sentencias o conceptos. Estos motivos se ilustran con lugares paralelos hallados en poetas que Cetina pudo leer, o que pudieron leerle. Cada vez que el poema hace intervenir a un personaje histórico, el comentario, completado por las notas, da cumplida información sobre dicho personaje en aquellos aspectos susceptibles de iluminar el contenido de los versos. A menudo el editor engasta en su anotación, una densa monografía sobre un tema importante y poco o mal estudiado. Buen ejemplo de ello son las casi cuatro apretadas páginas en letra menuda que dedica al secretario de Estado, Gonzalo Pérez, en su calidad de poeta y amigo de poetas, con ocasión del soneto (más amistoso que cortesano) que le dirigió Cetina (pp. 679-683). Resultado de la ingente suma de datos, de textos, de apuntes exegéticos así reunidos, el volumen puede aportar al lector atento una verdadera iniciación al mundo de Cetina. De su lectura pausada salimos habiendo tratado, de la mano del poeta y guiados por Jesús Ponce, a miembros de la aristocracia como Ferrante Gonzaga, príncipe de Molfetta, su mujer Isabella de Capua, el embajador Diego Hurtado de Mendoza, el capitán y gobernador Luis de Leyva, príncipe de Áscoli, don Gonzalo Fernández de Córdoba, tercer duque de Sessa ${ }^{15}$; a soldados, cortesanos y humanistas como Jerónimo de Urrea,

Notes, 31/2 (1916), pp. 122-123). Otro soneto muy difundido que imita Cetina, esta vez de autor famoso, es el dedicado por Baltasar de Castiglione a las ruinas de Roma (en cuya grandeza que resistió al tiempo, y acabó cediéndole, ve una esperanza de que su tormento, igualmente grande y persistente, un día tenga fin), «Superbi colli, e voi sacre ruine.» Según Herrera, Gutierre de Cetina lo tradujo «con grande spiritu» en su soneto «Excelso monte, do el romano estrago». Aunque la verdad es que en este caso, Cetina no traduce: recoge algunas perlas del modelo e inventa un nuevo hilo para ensartarlas. Podría mostrarse que también cuando se inspira en poetas famosos a los que sigue en bastantes poesías, el sevillano suele seleccionar para imitarlos textos de antología, aplaudidos y celebrados, como el de Tansillo, "Poi che spiegate ho l'ale al bel desio», que citará Giordano Bruno en sus Eroici furori. Este soneto cifra de modo monumental y memorable, de una vez por todas, la figura del amante como Ícaro, ya apuntada en Petrarca, y elaborada con especial felicidad en la poesía napolitana desde Sannazaro; tiene papel fundacional para el símbolo lírico asociado al héroe mitológico como lo tiene Castiglione para la "poesía de las ruinas» cultivada por el Renacimiento italiano y luego europeo. Es posible que sobre muchos motivos y conceptos del petrarquismo suceda algo parecido: existe un poema, a menudo un soneto, más rara vez una canción o madrigal, que desarrolla el motivo o concepto de manera luminosamente acabada, con riqueza y equilibrio clásicos, constituyendo a partir de ahí el texto una referencia obligada siempre que se toca el motivo o se rehace el concepto. Incluso poetas de talento mediano y producción ocasional pueden esperar escribir uno de estos textos que quedan fijados en la memoria literaria, y ser recordados por él, aunque no puedan saber cuándo y cómo las caprichosas Musas y la inescrutable fortuna les serán favorables, lo que tal vez contribuya a explicar la multitud de poetas de corte y de academia que proliferan en el XVI. Algo así le pasó a Cetina con su madrigal «Ojos claros, serenos» de cuyo éxito excepcional (aunque, al parecer, limitado a España) él no podía tener la menor idea cuando lo escribió.

15. Cetina tuvo trato con este y otros políticos y militares espańoles e italianos de alta alcurnia y carrera brillante en el entorno imperial. Todos ellos trabaron entre sí relaciones amistosas de cierta duración y consistencia (pese a la dispersión que acarreaban los constantes desplazamientos 
Jorge de Montemayor, Juan de Rojas Sarmiento; a numerosas damas, bastante desdibujadas como individuos, de las diversas cortes por las que anduvo Cetina -Valladolid, Palermo, Nápoles, Milán-; a clérigos y letrados de Sevilla, o del área catalana, como mosén Onofre Gualbes, identificado por Jesús Ponce como el destinatario de la epístola «a Pavordre Gualbes» (pp. 1076-1081). Este representante del alto clero y de los círculos humanistas catalanes, que ostentó el cargo de Administrador del studium de Barcelona (1544-1559), pudo ser el interlocutor a quien debió el poeta su frecuentación asidua de Ausias March ${ }^{16}$. En definitiva, leemos en estas Rimas la poesía de Cetina, y a un tiempo vemos al hombre en cierto modo redivivo, actuando en la red de relaciones sociales que lo constituyó como sujeto, determinó sus preocupaciones y modos de sentir y en la que se sitúa su voz.

Por lo demás, la introducción dedica una importante sección a la fama y al influjo de Cetina en las generaciones posteriores: «Un poeta ante la historia. El primer canon bético» (pp. 174-178). Se citan ahí y se comentan con agudeza extractos de Fernando de Herrera, Luis Barahona de Soto, Juan de Mal Lara, Cristóbal de Mesa, Juan de la Cueva, Francisco Pacheco, que permiten apreciar la amplitud y la hondura del recuerdo dejado por nuestro poeta en la segunda mitad del siglo, en las dos vertientes del amor y del humor, de la lírica amorosa y de la poesía festiva.

Por esta segunda faceta de su talento, Cetina hizo oficio de mediador entre la poesía satírica de Italia (en la estela de los dos grandes modelos -opuestos entre sí- de la sátira renacentista italiana, Lodovico Ariosto y Francesco Berni), y por otro lado la floreciente poesía jocosa sevillana de finales de siglo, fermento a su vez de la rica producción «burlesca» española del siglo XVII. Sintomática resulta su relación con el gran maestro de las «sales sevillanas», Baltasar del Alcázar (1530-1606), quince años más joven que Cetina, y que perteneció como él a una estirpe de ricos hacendados conversos con fama y costumbres de hidalgos, que lograron brillantes carreras en la alta administración municipal, eclesiástica o cortesana. De la amistad de Alcázar con Cetina (cuando este último, ya de regreso a Sevilla, debía de ocuparse de la gestión de negocios familiares) dan testimonio Pacheco en el Libro de retratos (1599), los cuatro entusiastas sonetos de elogio escritos por el joven Alcázar ${ }^{17}$, y las dos epístolas que intercambiaron ambos escritores. Significativamente versan sobre los tópicos más frecuentados,

del Emperador y de sus servidores entre las numerosas «cortes» efímeras o subsidiarias repartidas en buena parte de Europa) gracias al cultivo de la poesía, y singularmente de la poesía amorosa de clave pastoril, por lo cual Cetina los designa con senhales bucólicas: Pirenio para el secretario Gonzalo Pérez, Lavinio para don Luis de Leyva, Sesenio para el duque de Sessa, don Gonzalo Fernández de Córdoba, Lusitano para Jorge de Montemayor, y Vandalio, para el mismo Cetina. Para todo ello, léase, además de la introducción de Rimas, el estudio de Jesús Ponce Cárdenas, "Cauces de la imitación en el Renacimiento: Gutierre de Cetina y Nicolò Franco», e-Spania. Revue interdisciplinaire d'études hispaniques médiévales et modernes, 13 (2012), pp. 1-37.

16. Jesús Ponce tiene en prensa un artículo al respecto, «Gutierre de Cetina y Onofre Gualbes: dintornos de una epístola», Hispanic Research Journal.

17. Sonetos 1 a 4 en edición de Valentín Núnez Rivera, véase nota siguiente. 
y en cierto modo definitorios, de la epístola de tipo horaciano-ariostesco: el tedio de vivir en el campo, alternando con rústicos villanos (asunto que se presta a un ethos jovial y escéptico) y el disgusto de hallarse en la ciudad, en medio de la feria de las vanidades, ambiciones y mentiras (tópico de índole más amarga, y propicio a reflexiones morales de signo más o menos estoico $)^{18}$. Muy apropiadamente es el joven Alcázar quien inicia la correspondencia tratando el primer tema; y el maduro Cetina quien le contesta con el segundo. Sobre todo ello, ofrecen las Rimas que reseñamos cumplida información y sustancioso comentario (pp. 1118-1132).

En la vena amorosa, se verifica el papel de mediador desempeñado por Cetina para el petrarquismo hispanizado iniciado por Boscán y Garcilaso y que iba a convertirse en el idioma común de la poesía al menos hasta las primeras generaciones del siglo XVII. Se trasvasa entonces definitivamente en el «toscano» de Petrarca y de Boccaccio, adoptado como lengua literaria en toda la geografía italiana, la herencia del humanismo del Quattrocento, un humanismo de filólogos, en el más noble sentido del término, y de escritores latinos o bilingües, para quien el latín es modo de expresión natural y privilegiado.

Italia, en el segundo tercio del siglo XVI, intenta reponerse de la traumática inestabilidad política y de la interminable guerra de décadas anteriores, al precio de una pérdida de «libertad» a la que muchos se resignan no sin amargura. Este país en grave crisis sigue teniendo a su favor una producción deslumbrante en calidad y cantidad en todas las áreas de las letras, el pensamiento, los saberes y las artes. Los españoles, asentados en la Italia meridional ya a finales de la Edad Media, cosechan a lo largo del siglo XVI en ventajas materiales y simbólicas los éxitos militares y diplomáticos de su monarquía, que domina desde el Milanesado a Sicilia y se convierte en potencia hegemónica en Europa, logrando relegar a Francia al precio de una lucha agotadora. No obstante, en número de personas alfabetizadas, de poetas con cultura humanística, de eruditos helenistas o expertos en antigüedades, de plumas elocuentes, de damas cultas, de libros impresos, de arquitectos, escultores, pintores, artesanos del metal, de la madera, de la piedra o del tejido, botánicos, ingenieros, matemáticos, filósofos naturales, músicos doctos, toda España, por aquel entonces, pesa tal vez menos que Nápoles, Roma, Florencia o Venecia, no mucho más que Génova, el Milanesado o Sicilia. En la época de actividad de Cetina, el segundo tercio del siglo XVI, los españoles son algo más que receptores ávidos de las obras creadas en Italia y dispuestos a tomar en préstamo aspectos de su cultura, como lo son ya por entonces los franceses y lo serán, algo más tarde, los ingleses y la mayoría de los europeos. Llamados a inmiscuirse en posición de fuerza en los asuntos internos italianos, llevando como vanguardia una pequeña élite de nobles, clérigos, letrados mercaderes y soldados que allí viajan por afán de aventuras o deseo de medro, los naturales de los diferentes reinos de la Península ibérica son arrastrados por el torbellino de una cultura de inaudito

18. Baltasar del Alcázar, Obra poética, ed. de Valentín Núñez Rivera, Madrid, Cátedra, 2001, pp. 21-22. 
vigor, por una literatura en plena fase de unificación sobre nuevas bases y en nuevas condiciones políticas y lingüísticas, dominada ahora por una lengua vernácula de uso cada vez más amplio, cuyo manejo al menos pasivo resulta facilísimo a los españoles más avispados y con algún bagaje de letras latinas. De lo que resulta la integración de España, como una parte más, casi una provincia aunque de particularidad irreductible, en un movimiento complejo cuyo excipiente linguístico-literario, y cuyo exponente más vistoso entre las élites cortesanas, es el nuevo petrarquismo ${ }^{19}$.

Ahora bien, Gutierre de Cetina se encuentra inmerso en el ambiente de la Italia española en la década que tal vez marca el ápice del petrarquismo del "Cinquecento», fenómeno de distinta naturaleza y alcance que otras modalidades, anteriores, de imitación de Petrarca. La pujanza de este fenómeno que se fragua en pequeños círculos cortesanos y urbanos de nobles y letrados, irrumpe en oleadas sucesivas, en una esfera pública extendida a toda Italia, y pronto a toda Europa, cimentando la unidad cultural de la península y contribuyendo a la expansión extrapeninsular de la cultura italiana. A ello contribuyó desde mediados de siglo la impresión, que debió arrojar pingües beneficios, de una serie de copiosos cancioneros colectivos. El momento álgido de esta actividad de las prensas se sitúa entre 1545 y 1570 aproximadamente, y la iniciativa procedió de un gran impresor veneciano con gran sentido del negocio editorial, Gabriele Giolito de Ferraris. Éste inicia la serie de los volúmenes colectivos de Rime diverse (nueve partes o libros, con muchas reediciones), a los que seguirán pocos años más tarde antologías de antologías, las selectas Rime scelte y Fiori d'illustri poeti. En el conjunto de estos volúmenes se recogen miles de textos de centenares de poetas de todas las regiones de Italia ${ }^{20}$. Los años de estancia de Cetina en Italia (de finales de la década de 1530 hasta finales de la década siguiente) coinciden con este momento que marca, con un segundo nacimiento de la poesía, el despegue definitivo de la lengua vernácula como vehículo preferente y casi exclusivo de toda creación verbal, poética y oratoria ${ }^{21}$.

19. Sobre este dilatado campo, una obra colectiva reciente que reúne contribuciones de los mejores estudiosos del tema puede constituir una buena base de estudio: Il Petrarchismo. Un modello di poesia per l'Europa, Vol I, ed. Loredana Chines, Roma, Bulzoni, 2006. Acerca del caso español en su relación con Nápoles, debe leerse el ensayo, recogido en el citado volumen, del gran especialista del Renacimiento meridional Tobia R. Toscano, «I petrarchisti napolitani e il Siglo de oro", pp. 217-240.

20. Véase Roberto Fedi, "Canzonieri e lirici nel Cinquecento», La memoria de la poesia. Canzonieri, lirici e libri di rime nel Rinascimento, Roma, Salerno, 1990 , pp. 23-51; Amedeo Quondam, "Strumenti e tipologie editoriali del petrarchismo», Il naso di Laura. Lingua e poesia lirica nella tradizione del classicismo, Ferrara-Modena, ISR-F.C. Panini, 1991, pp. 123-150; Monica Bianco y Elena Strada (eds.) "I più vaghi e più soavi fiori». Studi sulle antologie di lirica del Cinquecento, Alessandria, Edizioni dell'Orso, 2001.

21. Entre la vasta bibliografía al respecto son fundamentales los trabajos de Carlo Dionisotti, especialmente sobre Pietro Bembo, recogidos en un volumen póstumo, Scritti sul Bembo, ed. Claudio Vela, Turín, Einaudi, 2002. También el libro de Amedeo Quondam citado en la nota anterior y el de Giancarlo Mazzacurati, Il Rinascimento dei Moderni. La crisi culturale del XVI secolo e la negazione delle origini, Bologna, Il Mulino, 1985; véase también el ensayo 
A la incorporación o más bien a la agregación de la cultura hispánica a lo que está sucediendo en Italia, que se acelera en la década de 1530, coincidiendo a la vez con la hegemonía del petrarquismo y con la construcción de un poder virreinal fuerte en Nápoles, contribuye en modo muy seńalado este inquieto hidalgo sevillano, por la variedad de frentes que abre y por la influencia que sus experimentaciones ejercen en poetas de su generación y de las siguientes.

Los pormenores de esta influencia son uno de los muchos aportes de la edición de Jesús Ponce, quien demuestra los esfuerzos pioneros del poeta sevillano, en los campos del madrigal en que su «excelencia de primero", como diría Gracián, es más notoria; de la elegía, de la epístola (géneros en los que sucede inmediatamente a sus primeros cultivadores en castellano, Boscán y Garcilaso); del epigrama, del capitolo y de la carta amorosa en tercetos, de las composiciones ecfrásticas asociadas a una pintura o retrato (prácticas poéticas en que comparte la primacía con Diego Hurtado de Mendoza). Estos textos de nueva planta incitaron a poetas castellanos, y en primer lugar a muchos andaluces, que no habían tenido su experiencia italiana, a proseguir por los derroteros por él marcados. Valora también el editor con impecable precisión la importación por Cetina de microgéneros nacidos en Italia, y que proseguirán su trayectoria en Espańa a veces hasta entrado el siglo XVII: los enfados, transposición de las noie, inauguradas por el florentino Antonio Pucci en el siglo XIV y de que Cetina escribe el primer testimonio hispánico en su Epistola en forma de enfados, probablemente dirigida al duque de Sessa (p. 1088-9) ${ }^{22}$; la cantilena oculorum, término empleado por Petrarca para un poema suyo, que iniciaría una cadena de textos similares (pp. 112-114); la canción «disperata» inventada por Saviozzo y cultivada por los petrarquistas cortesanos de finales del Quattrocento como Tebaldeo (pp. 114-117); la partita y la ritornata, subgéneros del capítulo amoroso; el escondit trovadoresco, que «se difundió en la lírica italiana a partir de la canción CCVI de Petrarca»; la mascarada, «naciente género áulico cultivado en Italia por dos de los autores más admirados del momento, Pietro Bembo y Luigi Tansillo» (p. 118), que inaugura Cetina en castellano con su poema "en máscara de diez peregrinos» en veinte octavas reales, escrito para los festejos carnavalescos de la corte virreinal de Palermo.

Con este italianismo multiforme y militante contrasta el magisterio del valenciano Ausias March (1397-1459), poeta de cultura escolástica y trovadoresca, de corte prehumanístico ${ }^{23}$, cuyo potente influjo en la poesía de Cetina descubrió, a principios del siglo XX, Alfred Miles Withers ${ }^{24}$. Jesús

Marco Santagata, «Nascere due volte», I due cominciamenti della lirica italiana, Pisa, ETS, 2006, pp. 7-34. La fecha de 1530 en que se imprimen las Rime de Pietro Bembo y los Sonetti e canzoni, de Sannazaro, marca convencionalmente el arranque de este proceso.

22. Véase Rafael Lapesa, «Enfados y contentos en la poesía española del siglo XVI», Filología XX (1985), pp. 75-109.

23. Begoña López-Bueno indicaba cuarenta y seis casos de manifiesta o muy probable influencia de March (Gutierre de Cetina, Sonetos y madrigales completos, ed. B. López Bueno, Madrid, Cátedra, 1981, nota 84, p. 44).

24. The Sources of the Poetry of Gutierre de Cetina, Philadelphia, Pennsylvania University, 
Ponce transcribe en sus notas los pasajes de March en que se inspiran muchas composiciones de Cetina, y consigna también la traducción castellana de Jorge de Montemayor ${ }^{25}$, cuya versión de los poemas marquianos fue impresa en 1560 (no siempre, hay que decirlo, resulta muy fiel o acertada esta traducción). Cetina suele tomar de Ausias March un pensamiento o sentencia de los muchos tan vigorosamente forjados por este poeta y se sirve de él como punto de partida, aunque por lo general tiende a debilitarlo y a diluirlo en el petrarquismo ecléctico que es la base de su discurso amoroso y de su cultura poética. No queda del todo claro hasta qué punto dominaba el catalán y era capaz de leer de primera mano a un poeta tan difícil como March, aunque las estupendas notas de nuestra edición contienen numerosos materiales y observaciones que permitirían abordar el problema ${ }^{26}$. Cetina, como otros petrarquistas españoles y portugueses de su tiempo, Diego Hurtado de Mendoza, Jorge de Montemayor, Luis de Camoens, se apoya en el poeta de expresión catalana, posiblemente para contrapesar mediante una voz y doctrina propias la avasalladora influencia de Italia, escapando así al reproche de trivialidad o hasta de plagio («hurto») al que se exponen merecidamente las imitaciones en castellano de los seguidores italianos de Bembo o de Sannazaro, a su vez imitadores de Petrarca. Es posible que imitara a March para corregir la superficialidad de cierto petrarquismo mediante la hondura y gravedad del poeta catalán, o sea por razones similares a las que llevaron a ciertos italianos de esos mismos años a acogerse al magisterio de Dante. Con ello Cetina prolonga, con mayor perseverancia, la tarea de convertir a March en distintivo de una lírica amorosa a la vez italianizante e ibérica, que ya emprendieran Juan Boscán y Garcilaso de la Vega. También en este aspecto, constituye un eslabón importante en la fundación de una poesía española moderna.

Como concluye Jesús Ponce, es característico de Cetina el afán de cubrir el mayor número posible de territorios y de anexar nuevos estilos y formas, síntoma tal vez del dinamismo ascendente de su ciudad y de su linaje. Aunque sea difícil deducir nada de una ausencia, querríamos hacer notar que pese a su notable variedad, hay algo que falta con plenitud en estas Rimas, a saber cuanto atañe a la religión, ya sea desde el ángulo circunstancial, devocional y ceremonial, ya desde el espiritual. El tema aflora más que discretamente en escasísimos textos y sólo domina, salvo error por nuestra parte, en un madrigal

1923; «Further influences of Auzias March on Gutierre de Cetina», Modern Language Notes, LI, 1936, pp. 373-379.

25. Véase, acerca de esta traducción, publicada en Valencia en 1560, Lourdes Sánchez Rodrigo y Enrique J. Nogueras Valdivieso, «Ausiàs March y Jorge de Montemayor: traducción e interpretación». Annexes des Cahiers de linguistique hispanique médiévale, volume 14, 2000. Ausias March (1400-1459). Premier poète en langue catalane. pp. 357-374.

26. No se conoce la fecha de la muerte de Cetina en México, aunque sí que es anterior a 1557. No pudo pues tener acceso a la edición de la traducción de Montemayor de 1560 aunque sabemos que lo trató, por un intercambio de cartas poéticas. No puede por lo tanto excluirse que «Lusitano» le comunicara todo o parte de sus traducciones de March, mucho antes de imprimirlas. 
«iAy de mí, sin ventura» (p. 727-728) del que se conoce una sola copia, recogida en el Cancionero sevillano de Toledo y que Jesús Ponce añade al magro aunque famoso corpus de los cinco madrigales hasta ahora conocidos. Se trata del «monólogo dramático» de una monja que se queja de su miserable estado, de la «regla pesada», del "coro importuno», y en suma de la tiránica ley que la condena a una privación de libertad a la que sólo pondrá término la muerte. No es el único caso de protesta frente a la ingrata y estéril vida conventual a la que eran condenadas muchas mujeres, como lo ilustran los textos paralelos acopiados por Ponce (de Sebastián de Horozco, Luis Hurtado de Toledo, Cristóbal de Castillejo), pero cobra un patetismo inusitado en una forma, la del madrigal, afectuosa por excelencia.

De modo que esta vistosa excepción a la regla de la omisión del tema sacro en el corpus cetiniano, corrobora una frialdad religiosa que no es menos evidente en Garcilaso de la Vega, pero sorprende más en Cetina, que vivió algunos años más, conoció la Italia del Concilio de Trento, entrando tangencialmente en la órbita de la llamada Contrarreforma, y escribió bastantes más textos que el toledano, y con mayor variedad de registros. Los materiales reunidos por Jesús Ponce permiten confirmarlo con otro pequeño dato. Para el soneto CIX, «iOh sol, de quien es rayo el sol del cielo..." no había sido identificada la fuente italiana por los estudiosos, Alfred. M. Withers, Joseph G. Fucilla y Begoña López Bueno, que habían hasta hoy investigado con mayor celo el entramado intertextual de la poesía cetiniana. Jesús Ponce descubre que es una indudable adaptación del soneto "O sol, di cui questo bel sole è raggio», publicado en las Rime in morte di messer Carlo suo fratello que se añadieron como sección aparte en las últimas versiones de las Rime de Pietro $\mathrm{Bembo}^{27}$. El soneto bembiano está dirigido a Dios y es uno de los textos «de arrepentimiento» o, más bien, de conversión al amor divino que escribió en edad bastante avanzada y, según sospecha Dionisotti, para facilitar su disputado nombramiento como cardenal ${ }^{28}$. En cambio el poema de Cetina, cuyos cuartetos traducen los del poema italiano, se resume en una declaración de fidelidad y amor eterno a la dama, pese al tiempo transcurrido en ausencia. Se cierra con una declaración que, por su galante idolatría, no desdice de la religio amoris de los cancioneros hispánicos de principios de siglo XVI:

27. Jesús Ponce copia el soneto de Bembo (p. 422) en el comentario que precede las notas pero no indica de dónde lo saca, aunque parece probable que sea una de las ediciones modernas del poeta veneciano, tal vez la de Dionisotti en Einaudi. De hecho, el soneto figura en el ya citado cancionero colectivo dedicado al embajador Hurtado de Mendoza por Lodovico Domenichi, Rime diverse di molti eccellentissimi autori, Venezia, 1545, en la página 19. El verso 9 presenta en este cancionero una variante redaccional.

28. Pietro Bembo, Le rime, a cura di Andrea Donnini, Roma, Salerno, 2008, 2 vols. Puede verse el soneto, que lleva el número 177 en I, pp. 409-10. El editor comenta: «Questo sonetto e il seguente hanno carattere penitenziale; furono composti probabilmente nel novembre 1538 e forse non fu estraneo il movente pratico di fornire dell'autore, in procinto d'essere nominato cardinale contra forti opposizioni, un'immagine più condicente a quella dignitä' (Dionisotti)». 
Temor de olvido, grave mal de ausencia, del tiempo el vario curso y de fortuna, y el mal de no te ver, estoy pasando.

Mas por rodar del cielo, sol y luna, no temas, claro sol, que tu presencia olvide, pues por la fe la estoy mirando.

Esta conversión «a lo humano» de un soneto sacro sirva para recalcar que Cetina no aprovecha la posibilidad que ofrece el petrarquismo de integrar en el decurso de los versos amorosos textos que marquen el desengaño del profano amor y la conversión (si no realizada, al menos deseada) del alma a su Creador ${ }^{29}$. El hecho resulta más curioso si apreciamos su contraste con lo que puede observarse en los autores favoritos del mismo Cetina, o sea los imitados más pedisecuamente y al parecer con mayor reverencia: Petrarca y Luigi Tansillo. La obra de estos poetas, aunque de signo humanístico y por lo tanto de retórica y hábitos estilísticos aprendidos en los clásicos, y aunque su parte más notable se dedique a enaltecer el amor profano, deja ver la huella de un cristianismo ferviente o inquieto. Jacopo Sannazaro (c. 1458-1530) y Luigi Tansillo (1510-1568), cuyo genio poético domina el Renacimiento meridional en dos momentos clave sucesivos de la historia del reino de Nápoles (ocaso de la dinastía aragonesa y consolidación del poder virreinal) ${ }^{30}$ destinaron a un asunto sagrado sus dos poemas últimos y más ambiciosos: De partu Virginis (1526) para el primero, y Le lagrime di San Pietro (princeps póstuma de 1585) (11 $^{31}$ ara

29. El soneto CXIX (203 en la numeración de Sonetos y madrigales), «Solía cantar de amor dulces clamores», contiene, es verdad, una confesión de escarmiento, una admonición a los que se creen felices en amor, advirtiéndoles que esperen "nuevo mal, tormento extrańo» que se les «apareja al fin de los amores». Se cierra proponiendo como ideal la renuncia a la ambición : «Dichoso aquel a quien concede el cielo/ medir con su fortuna sus cuidados/y vive en un estado satisfecho.//Las altas esperanzas vanse a vuelo/ con el humo del mundo y sus estados/ y pierde más quien más de esto ha hecho» Por ello, Begońa López Bueno lo interpreta como "epílogo» del cancionero hipotético que ella reconstruye, y lo coloca al final de los sonetos amorosos, antes de comenzar los encomiásticos : «...en el expresivo soneto final, soneto-epílogo con el consiguiente aviso a los jóvenes a través de su propio escarmiento, termina con una reflexión moral : es la consigna de la serenidad, lección de humanismo que estrechamente recuerda a Fray Luis.» (Sonetos y madrigales..., ed. cit., p. 57). Es cierto que se trata de uno de los pocos textos de Cetina donde se expresa esta moral desengańada y que se puede muy bien colocar al final de los poemas amorosos, pero dada la escasa consistencia de la serie entendida como progresión hacia un posible arrepentimiento, muy bien podría haber sido escrito en un momento de desaliento, o como simple ejercicio. En todo caso, el matiz religioso que en él cobra el desengaño es muy débil y lo más interesante del soneto, a nuestro entender, es la amalgama que en él se opera entre el amor y la ambición.

30. Como se desprende de un ensayo clásico acerca del tema : Ezio Raimondi, «Il petrarchismo nell'Italia meridionale», Rinascimento inquieto, Turín, Einaudi, 1994, pp. 267-303. El trabajo ya había aparecido en Premarinismo e pregongorismo, Roma, 1973.

31. Para la complicada historia de la elaboración y transmisión de este poema, véase Luca Torre, La doppia edizione de "Le lagrime di San Pietro" di Luigi Tansillo tra censura e manipolazione. Tesis de doctorado dirigida por Tobia R. Toscano y Corrado Calenda, Università degli Studi di Napoli Federico Secondo, Nápoles 2010. 
el segundo. Si tenemos en cuenta la visión corriente de la España del Siglo de Oro como dominada por un catolicismo que no solo controla férreamente los comportamientos sino invade las conciencias, no deja de ser notable que hombres como Cetina vivieran, o a lo menos escribieran, abstrayéndose de las preocupaciones religiosas que tanto pesaban en el ánimo de la mayoría de los europeos. En una Europa soliviantada por fermentos de renovación espiritual que llevan a los laicos a terciar en el debate teológico, no son pocos los españoles, y entre ellos se cuentan varios escritores de primerísima fila, de Garcilaso a Góngora pasando por Cervantes, que trazan una línea divisoria infranqueable entre la esfera profana en que se mueven social y literariamente y la esfera de lo sacro, a la que prefieren asomarse lo menos posible en sus escritos. Lo que sugiere, o por lo menos parece sugerir, que el temor (reverencial o cauto) a la Inquisición tenía en ellos bastante más fuerza que el pavor al infierno.

De la obra poética de Cetina (c. 1505-c. 1555) existían hasta ahora dos ediciones; la decimonónica de Joaquín Hazañas y la Rúa, poco accesible y forzosamente superada, y la de los Sonetos y madrigales (Madrid, Cátedra, 1981), trabajo benemérito de Begońa López Bueno, que, al limitarse a dos formas breves, excluía gran parte de las poesías, puesto que no contiene, como recapitula Jesús Ponce «las canciones, las odas, la sextina doble, la Fábula de Amor y Psique, las estancias, los capítulos, las epístolas, las traducciones de las Heroidas y finalmente el conjunto de las composiciones en arte menor (romances, glosas y chistes) $»^{32}$ que sí figuran en la presente edición. Ciertamente los sonetos destacan entre las poesías del sevillano, por su elevado número (Ponce ha encontrado dos sonetos más que ańadir a los 247 sonetos editados por López Bueno $^{33}$ ) como por su variedad. Parece indudable que en el cauce del soneto se forja el arte de Cetina. Los madrigales merecen una consideración particular por la precocidad en el cultivo de esta forma y por la extraordinaria fama de uno de ellos (el inevitable pero hermoso «Ojos claros, serenos»). Sin embargo

32. He aquí el recuento de estas formas, tal como se presenta en Rimas: sonetos (249); madrigales (6); canciones en estancias al modo de Petrarca (11); odas o canciones en liras (2 más una «anacreóntica» en heptasílabos cuya atribución a Cetina no tiene mucho fundamento, según el propio editor, puesto que se basa en la presencia de la senhal «Dórida» y en la autoridad del Parnaso español de López de Sedano, 1773); sextina doble (1); epyllion o fábula en octavas (1); estancias en octava rima (9); capítulos (2); elegía (1); epístolas (15); traducciones de las Heroidas (3); romances, glosas y chistes (10). Las diferencias entre capítulos, elegía, y epístolas no son muy nítidas, y en los tres géneros Cetina utiliza tercetos encadenados salvo en el caso de una epístola en verso suelto a Isabella di Capua, princesa de Molfetta.

33. Sonetos CCVIII, «Nacido soy de amor, de amor criado» y CCXLIX, «El que de hidropesía está doliente». El primero fue publicado por J. J. Labrador y R. Di Franco, Poesías inéditas de Pedro de Padilla y versos de otros ingenios del siglo XVI. Ms. B90-VI-08 de la Biblioteca Bartolomé March, México, Frente de afirmación hispanista A.C., 2011, p. 580. El segundo, de que da noticia un incipit copiado en el principal manuscrito cetiniano, el RAE R. M. 6939, ha sido hallado por Jesús Ponce en un cartapacio de la Biblioteca Universitaria de Salamanca: Ms. 2007, fol. 56v, confirmando una intuición de Antonio Rodríguez-Mońino, que, sin embargo, no había podido dar con el texto. Véase el comentario del soneto en Rimas, p. 708. En un manuscrito posterior, aparece atribuido a Francisco de la Torre, pero es casi seguramente de Cetina. 
la integración de los demás géneros a las Rimas de Cetina da de él una imagen no sólo más completa, sino más fidedigna. En efecto, como hemos apuntado, la flexibilidad y la curiosidad, a la que sólo puede hacerse justicia viendo la totalidad de sus versos, son tal vez lo más propio de su figura. En contacto precoz con Italia, puesto que los primeros documentos de su larga estancia en aquella península tienen fecha de 1538, cuando Cetina contaba poco más de veinte años, y pronto al servicio de un noble, Ferrante Gonzaga, que por su brillante carrera como militar y político fue pieza maestra del dispositivo de la "Italia española», Cetina emprendió un esfuerzo sostenido de sumarse a las variadas experimentaciones que se llevaban a cabo en esos ańos cruciales para la literatura. Aunque es muy poco lo que podemos saber del modo en que el interesado concebía su oficina poética, puesto que, al igual que la gran mayoría de sus coetáneos españoles y como muchos italianos, en especial meridionales, no reunió sus textos para la imprenta, ni escribió prosas destinadas a explicarse al respecto, sí pueden espigarse noticias en uno de los géneros que cultivó de modo pionero: la epístola familiar, cercana al modelo ariostesco, con algo de crónica personal, en que se deja constancia estilizada de una vida, de un modo de situarse frente a ella, de unas inquietudes y ambiciones.

Cetina escribió cinco composiciones de estas características, estupendamente comentadas y anotadas por Jesús Ponce, que pone de relieve, para explicar los contornos de este género felizmente ensayado por Cetina, lo que el mismo poeta escribe al respecto en unos tercetos de su epístola a Luis de Leyva:

Los citados tercetos establecen una separación neta entre el amor y el humor o - dicho en términos cetinianos -entre las 'delicaduras' y las 'locuras'. Creo que, de alguna manera, estas estrofas marcan un importante cambio estético, un punto de inflexión, puesto que permiten contemplar una destacada parte de su correspondencia en verso bajo la especie de las cartas familiares del género jocoso. (Rimas, p. 98)

Por nuestra parte nos gustaría poner de relieve un testimonio sobre la postura de Cetina como poeta contenida en otra de estas cartas familiares, la 'Epístola a Diego Hurtado de Mendoza', interesante pieza muy bien comentada por Ponce (pp. 1096-1117) y ya antes estudiada por José Manuel Rico ${ }^{34}$. Al dirigirse a su corresponsal, con la timidez propia de un hombre de posición más humilde, Cetina vacila acerca del asunto sobre el que versará su carta en verso. Quiere escribir y busca sobre qué hacerlo, situación típica de la carta familiar, en donde importa no de qué se habla, sino a quién, pues sólo cuenta la amistad que la carta, por su mera existencia, por su deleitable elegancia y por el tono de sinceridad y confianza, contribuye a definir, proclamar y mantener. Por ello no rige el precepto retórico de la unidad y la carta tratará no un tema, sino dos sucesivamente. Cetina se hace primero cronista militar (casi reportero, diríamos hoy) de la campaña del ejército imperial, mandado por Ferrante Gonzaga, contra el duque de Clèves y luego contra su aliado Francisco I de

34. José Manuel Rico García, «La epístola de Cetina a don Diego Hurtado de Mendoza», Philologia Hispalensis, IV (1988), pp. 255-274. 
Francia (vv. 52-153). La segunda parte de la epístola desarrolla una sátira de la corte (vv. 154-270) ensayando un tópico que aquí se vierte, tal vez por primera vez en castellano, en la forma de la epístola en tercetos que se volverá cauce preferente para la censura de los males cortesanos; forma en la que será tratado el tópico por otros ingenios y con clásica perfección por los hermanos Argensola. Sin embargo estos temas los elige Cetina, según declara en el exordio de su epístola, después de haber considerado la posibilidad de tratar de amores (que él mismo realizará en su intercambio epistolar con Jerónimo de Urrea o en sonetos a Luis de Leyva), y haberla descartado, no por desdén, sino todo lo contrario. Se halla incapaz de medirse en el decir de amor con la excelencia de Boscán, con la gloria de Garcilaso, y con la elevación que ha logrado su propio corresponsal, don Diego Hurtado de Mendoza:

En una confusión estoy dudoso, que no sé qué os escriba que os agrade, que pueda al gusto vuestro ser sabroso.

De esta guerra he temor que os desagrade; del suceso de corte no hay qué escriba; de amor ¿ qué diré yo que no os enfade ?

La imagen de Boscán, que casi viva debéis tener, hará en vuestra memoria la más hermosa parecer esquiva.

Y el Laso de la Vega, cuya historia sabéis, de pïedad y envidia llena, digo, de envidïosos de su gloria.

Yo, que a volar he comenzado apena, apenas oso alzarme tanto a vuelo, que no lleve los pies por el arena.

Vos, remontando allá casi en el cielo paciendo el alma del manjar divino, ¿ quién sabe si querréis mirar al suelo ? (vv. 31-48)

Estas líneas, escritas a raíz de una campaña militar que concluye en el otoño de 1544, son pues poco posteriores a la muerte de Boscán (1542) y a la famosa prínceps de las Obras de Boscán y algunas de Garcilaso de la Vega (Barcelona, Carlos Amorós, 1543). Se desprende de ellas que la fama del primero y la "gloria» del segundo alcanzaban en aquel momento su cénit y que se volvía por ello imperativo, para un ambicioso hidalgo cortesano todavía joven (rondaba los treinta años) comenzar a "volar» por esta senda del decir «de amor»: algo que se relaciona con la hermosura, con la gloria, con la elevación del alma que se apacienta «del manjar divino». Este discurso amoroso al modo italianizante de Boscán, Garcilaso, Hurtado de Mendoza se le antoja en suma a Cetina empresa ilustre y difícil, reservada a nobles espíritus, de mucha gravedad y hondos 
afectos. En ella el sevillano se ve como aprendiz, como principiante, todavía en 1544. Ciertamente la declaración podría obedecer a la forzada y convencional modestia de rigor en la epístola, aun más cuando el texto se dirige, con tono no menos convencional de amistad y de igualdad, a alguien que no es un igual sino claramente un superior en todo: en edad, en sangre, en fortuna, en rango y en cultura. Por todo lo cual no debe ser tomada al pie de la letra. Sin embargo, tampoco hay motivos para rechazarla de plano. Sugiere que el sevillano empezó a cultivar el soneto y otras formas italianizantes de la lírica amorosa (la canción, la sextina, el capítulo) algún tiempo después de empezada su estancia en Italia, tal vez incluso ya bien entrada la década de 1540. Otro indicio de ello sería la importancia que tiene en su imitación de los petrarquistas italianos el volumen de Rime diverse (1545) compilado por Lodovico Domenichi e impreso por Giolito (que marca el comienzo de la inundación de cancioneros colectivos petrarquistas $)^{35}$. Este grueso y vario volumen debía de tenerlo muy a mano el sevillano, como señaló Begoña López Bueno ${ }^{36}$ y recuerda Jesús Ponce (p. 162). También manejó, como el mismo Ponce muestra, el segundo cancionero publicado por el mismo editor veneciano, Rime di diversi nobili huomini et eccellenti poeti nella lingua thoscana, Venecia, Gabriel Giolito di Ferrari, 1547, en el que se divulgó por primera vez la canción Quando'l sol parte e l'ombra al mondo cuopre, de Giulio Delminio, que adaptó Cetina en su canción Cuando la noche en el partir del día ${ }^{37}$.

35. Consúltese: su edición moderna, con excelentes introducción y anotación: Rime diverse di molti eccelentissimi autori,: Giolito 1545, eds. Franco Tomasi y Paolo Zaja, San Mauro Torinese, RES, 2001.

36. Cetina, Sonetos y madrigales..., ed. cit., pp. 39-40: «En la misma línea debemos entender las imitaciones de otros petrarquistas, si algunos reconocidos, como Castiglione (ss. 61, 132), Ariosto (s. 40), Sannazaro (s. 187) o Giraldi Cinthio (s. 2), otros de segunda fila como Marcello Philoxeno (s. 111), Bernardino Rota (s. 142), Serafino Aquilano (ss. 127, 180). E igualmente las ocho establecidas sobre otras tantas composiciones de Ludovico Dolce (ss. 5, 108), Giovanni Mozzarello (s. 64), Andrea Gesualdo (s. 71), Baltasar de Castiglione (s. 77), Francesco Coccio (s. 162), Trifone Gabriele (s. 207) y Pietro Bembo (s. 231), recogidas todas en la famosa antología de Rime diverse.. en 1545.». Véase también B. López Bueno, Gutierre de Cetina, poeta del Renacimiento español, ed. cit., p 106: "Crawford, estudiando a Hernando de Acuńa, otro poeta-soldado afín a Cetina en muchas circunstancias biográficas y literarias, supone que este autor conocería durante su estancia en Italia la famosa colección aparecida en Venecia, 1545, Rime Diverse di molti eccellentissimi authori nuovamente raccolte, porque de ella traduce dos composiciones, una de ellas el soneto de Giovanni Mozzarello que comienza 'Mentre i superbi tetti a parte a parte' 21 . Ocurre que Cetina también hizo una versión del famoso soneto, en el suyo 'Mientras con gran terror por cada parte', siendo éste uno de los ocho casos en que se inspira en composiciones incluidas en las Rime Diverse, según veremos luego. Lo que da pie para establecer la misma suposición que con respecto a Acuńa y aún con más motivo. Se da la circunstancia, además, de que esta colección estaba dedicada a don Diego Hurtado de Mendoza, gran amigo de Cetina. Sabemos también, por la epístola IX, dirigida a la Princesa de Molfeta, que Cetina estaba en Italia en 1545. Las Rime Diverse formaban una antología que contenía la mejor poesía de la escuela petrarquista, poesía que nuestro autor conocería de primera mano.». En realidad, creemos que el número de textos que Cetina pudo tomar de las Rime diverse fue algo superior al que indica la estudiosa.

37. Jesús Ponce ha rectificado la atribución de esta canción a Lodovico Ariosto, que se venía 
De hecho, fuera del mismo Petrarca, el principal autor que imitó con perseverancia Cetina, y al que no conoció a través de las citadas Rime diverse, fue su estricto contemporáneo Luigi Tansillo (1510-1568), el poeta más brillante de la Italia meridional de aquellos años, miembro de la guardia personal del virrey don Pedro de Toledo. Como soldado y cortesano que era, este caballero napolitano no se preocupó demasiado de imprimir sus poesías. El primer paso de sus versos por las prensas (fuera de una delgada «plaquette» con sonetos «a la presa d'Africa», impresos en 1551 en Nápoles) se dio a raíz de la inclusión de veintitrés composiciones suyas en otra de las antologías de Giolito, la tercera, de 1552, primera dedicada específicamente a una región de Italia, que, con título de Rime di diversi illustri signori napoletani, marca el nacimiento público del petrarquismo meridional ${ }^{38}$. Tobia R. Toscano ha descubierto (y Jesús Ponce se hace amplio eco de ello) que algunos de los poemas de Tansillo imitados (o traducidos) por Cetina no sólo no figuran en esta antología sino que no fueron impresos en parte alguna hasta las ediciones de Fiorentino (1882) y PércopoToscano (1926). Así sucede con la elegía Se quel dolor che va innanzi al morire, seguida por Gutierre de Cetina en sus tercetos Si aquel dolor que da a sentir la muerte. Como ha demostrado el doctísimo editor de Tansillo, la versión imitada por el sevillano no fue la impresa en 1552 en las Rime de Giolito, adaptada por Diego Hurtado de Mendoza, sino otra anterior más breve. Ésta se encuentra en el lujoso códice de Rimas que el poeta envió en enero de 1546 a don Gonzalo Fernández de Córdoba, tercer duque de Sessa, y que se conserva en la Biblioteca de la Universidad de Coimbra ${ }^{39}$. De hecho el estudio por el sabio italiano de los textos de Cetina a la luz de su exhaustivo y meticuloso manejo de la tradición textual de Tansillo, lo llevan a la conclusión de que el códice de Coimbra, ofrecido por el poeta napolitano al duque de Sessa, fue para Cetina un libro de cabecera:

...una sorta de 'livre de chevet' da cui ha attinto a piene mani sollecitazioni tematiche e stilistiche a tentare forme metriche nuove per la Spagna come il madrigale [...] Probabile che Cetina [...] lo abbia incontrato propio a Valladolid nella corte del principe Filippo, allorché vi giunse nell'aprile-maggio 1548, latore di lettere relative ai preparativi dell entrata in Milano, e che, prima di ritornarsene a Siviglia, sia stato messo a parte da Don Gonzalo del prezioso canzoniere, che nel gennaio del 1546, gli aveva mandato da Napoli Luigi Tansillo ${ }^{40}$.

repitiendo en los estudios cetinianos desde la edición de Hazaña de 1895.

38. Véase el magnífico estudio que de sus variantes, circunstancias, contenido y fortuna hizo Tobia R. Toscano, «Le Rime di diversi illustri signori napoletani: preliminari d'indagine su una fortunata antologia", Letterati, corti, accademie. La letteratura a Napoli nella prima metà del Cinquecento, Nápoles, Loffredo editore, 2000, pp. 183-200.

39. Véase Tobia Toscano, «Un libro di rime di Luigi Tansillo per don Gonzalo Fernández de Córdoba, III Duca di Sessa", Letterati, corti, accademie. La letteratura a Napoli nella prima metà del Cinquecento, Nápoles, Loffredo editore, 2000, pp. 144-182. Se apoya en este manuscrito el primer volumen de su reciente edición de Luigi Tansillo, Rime, ed. Tobia R. Toscano, Roma, Bulzoni, 2012, 2 vols.

40. Tobia R. Toscano, «I petrarchisti napolitani e il Siglo de oro», ed. cit., pp. 230-231. 
Todo lo que venimos diciendo incita a fechar la mayor parte de los poemas petrarquistas de Cetina en sus últimos años de estancia en Italia, o incluso del período de 1549-1553 durante el cual, en palabras de Pacheco, vuelto «a su patria y a la quietud de las Musas, estuvo retirado gran tiempo en una aldea fuera de Sevilla, a donde hizo gran parte de las obras que hoy parecen suyas».

Jesús Ponce ha optado por conservar el orden de los sonetos propuesto por Begoña López Bueno en su edición de 1981 (que no tiene base en los manuscritos), sin hacer suya, sin embargo, la decisión adoptada por esta estudiosa de integrar en la numeración de los sonetos los cinco madrigales entonces conocidos de Cetina (como hemos indicado, Jesús Ponce añade un sexto madrigal, recogido en el Cancionero sevillano de Toledo). A decir verdad, integrar los madrigales interpolándolos entre los sonetos no es suficiente para reconstituir un hipotético Canzoniere, como intentó valientemente hacerlo López Bueno. Para hacerlo tal vez hubiera sido necesario, si consideramos los ejemplos de Petrarca y del petrarquismo más ortodoxo, interpolar también los sonetos circunstanciales relegados al final, puesto que muchos de ellos, aunque dirigidos a personajes históricos, integran confidencias amorosas. En todo caso, tendrían que haberse colocado en su lugar conjetural las canciones italianas y los capitoli en tercetos (donde incluso aparecen en ocasiones las senhales de Vandalio, Dórida y Amarilis), y por supuesto, la doble sextina.

De hecho, dicha ordenación de los doscientos cuarenta y siete sonetos que debemos a la gran maestra sevillana -en este trabajo de su primera juventud-, y que Jesús Ponce respeta escrupulosamente, contentándose con añadir al final dos textos nuevamente descubiertos, facilita considerablemente la lectura, puesto que circunscribe, en la masa que podría ser informe de tan numerosas piezas poéticas, ciclos de sonetos cuyo parentesco mutuo salta a la vista. Los más nítidos son el que ella sitúa al comienzo, donde tanto el amante como las amadas aparecen bajo senhales bucólicas: Vandalio para el amante, sobrenombre con que muchos contemporáneos designaron a Cetina; Dórida y Amarilis para las damas. Otro «ciclo» situado más adelante, lleva la impronta de Ausias March y tiene un carácter más abstracto, introspectivo y atormentado. Un tercero situado al final agrupa los sonetos encomiásticos -CC a CCXLVII en la numeración de Rimas (2014); 204 a 252 en la de los Sonetos y madrigales (1981)-.Esta categoría de «encomiásticos» les es aplicada de modo aproximativo porque los últimos de la serie son epigramas burlescos o satíricos, algunos son de tipo epistolar y amistoso, y muchos, como hemos recordado, tratan de amor, aunque dirigiendo el discurso, a modo de confidencia, a un personaje que también está enamorado o podría estarlo. Dentro de estos grandes ciclos, algunas series breves se presentan como variaciones en torno a un tema: así los dos sonetos acerca de Leandro, CXII y CXIII (imitaciones claras de Garcilaso) o los dos acerca de Sísifo (LXXXVII y LXXXVIII); otros se agrupan porque elaboran una misma metáfora o alegoría: por ejemplo, al amante como nave expuesta a la tempestad se dedican ocho sonetos seguidos entre el CLIII y el CLX; otras series son variaciones de un concepto más singular o más complejo, como los mirabilia de la sangre vertida, aplicados al caso del herido de amor, 
o por ejemplo al ya muerto de amor, pero cuyas heridas vierten sangre en presencia de la dama, su matador (sonetos CXXIII-CXXV).

A la luz de las consideraciones que preceden, resulta en cambio inadecuada la ordenación si aspira a probar no tanto que Cetina proyectaba un verdadero Canzoniere de tipo petrarquista (cosa al fin y al cabo posible) sino que sea mínimamente viable la empresa de reconstruirlo con los materiales que nos han llegado, aunque sea de modo conjetural. Ciertamente los poemas de ambiente pastoril a Dórida y a Amarilis al principio del corpus de sonetos, permiten conjeturar un conato de novela que se situaría antes de la estancia en Italia: de Dórida, dama sevillana conocida en la primera juventud, se habría separado su amante Vandalio para ir (¿hacia 1536 o 1537 ?)a la corte que se hallaba entonces en Valladolid. Con inmotivada y confesada infidelidad a Dórida, se habría enamorado allí de otra dama, Amarilis, de origen navarro, quien lo habría seguido a Sevilla; más tarde la añoranza de la ausente Amarilis (presumiblemente dejada en España) habría convertido en doloroso exilio los años en Italia, o a lo menos los primeros ${ }^{41}$. Lo que implicaría, si se tratara de testimonios autobiográficos, escritos al calor de la pasión, que muchos de estos sonetos fueran fruto de la mocedad, compuestos antes de la partida a Italia o poco después (digamos, entre 1535 y 1540). En cambio los poemas inspirados en Ausias March, y más o menos agrupados hacia el final de la serie de sonetos amorosos, serían propios de un momento de mayor gravedad y madurez y habría que suponerlos fruto de lo que llama Pacheco el "retiro sevillano», después de 1548-1549:

De hecho, si hacemos dos calas en el cancionero dividiéndolo en tres secciones [...] que lo estructuran de modo coherente, resulta bien sintomática la progresiva influencia de Ausias March en detrimento de la italiana, especialmente cuando ya al final el poeta anhela un amor sublimado aquilatando grados ${ }^{42}$.

Se construye así, por adivinación, un «cancionero» petrarquista: secuencia de poemas líricos fruto de momentos de introspección y de fiebre sentimental luego recogidos, releídos y ordenados en una delgada trama seudo-narrativa. En estos poemas de diferentes metros ordenados en el tiempo pero sobre todo por la lógica del proceso subjetivo, se supone que el poeta ha ido dejando constancia de una pasión vivida durante varios o muchos años con dos vertientes inseparables, la del amor y la del afán de gloria, implicando este último la excelencia poética, pero también el compromiso ético-político. La construcción progresiva de una estética, acompañando el proceso de los amores desde el primer encuentro deslumbrado y esperanzado, a través de los momentos de exaltación y dolor de un deseo incurable, hasta el último desengaño, tendría que ir del predominio relativo de lo más ligero, sensual y tierno (la piacevolezza,

41. Con mucho ingenio asociado a una buena dosis de imaginación, desarrollaron este esquema hasta convertirlo casi en una verdadera novela Eugenio Mele y Narciso Alonso Cortés, Los amores de Gutierre de Cetina y su famoso madrigal, Valladolid, Imprenta Provincial, 1930.

42. Sonetos y canciones, ed. cit., p. 57. 
o lo deleitable, en términos del codificador del petrarquismo, Pietro Bembo) al de lo más profundo, doloroso y desengañado (la gravità, según el mismo Bembo), de modo tal que el cancionero en su conjunto, aunque no sin retoques embellecedores, dé cuenta de la verdad no de la vida exterior (aunque sí deba reflejarla en puntos muy determinados, incluyendo poemas relativos a las actividades mundanas del poeta, sus amistades y posturas políticas) sino de una experiencia invisible, de un itinerario sentimental, intelectual y espiritual ${ }^{43}$. En el caso de Cetina, la fragilidad de la construcción se vuelve patente si tenemos en cuenta que buena parte de su producción italianizante es posterior a las Rime diverse de 1545, y al «libro» de Rime ofrecido a Sessa en 1546 por Tansillo y que el sevillano pudo tener en manos y copiar total o parcialmente en 1548. Acaba de corroborar este carácter tardío, con respecto a la historia de los supuestos amores vividos, uno de más singulares y jugosos descubrimientos de Jesús Ponce. Un conjunto de composiciones del denominado ciclo de Dórida sigue de muy cerca el modelo de seis sonetos satíricos y lujuriosos integrados en una obra polémica, las Rime contro Pietro Aretino con la Priapea (Turín, Giovan Antonio Casale, 1541) del escritor beneventano Nicolò Franco ${ }^{44}$. Dejo a los lectores de las Rimas descubrir la apabullante transformación que sufren unos textos pastoriles paródicos, agresivos y salaces, al quedar convertidos en un dulce, lloroso y tierno canto de amor por Dórida. Así lo comenta Jesús Ponce:

El cantor de Dórida recurre a un 'modelo bajo' y lo ennoblece al transformarlo en un poema refinado o 'serio' invirtiendo los mecanismos habituales de la parodia, y filtrando cada uno de los elementos satíricos y obscenos presentes en el modelo. La manera de anular la carga cómica de las fuentes consiste en injerir en los nuevos sonetos elementos procedentes de la tradición bucólica elevada: la talla del dios Príapo en la corteza de un laurel da paso al motivo de la inscripcion arbórea del nombre de la amada ; el relato del hurto de un cabritillo por un pastor maligno se sustituye por el ataque de un lobo al rebańo; la contemplación ensimismada de los cuernos del personaje histórico vejado en las aguas de un arroyo se transforma en la admiración ante la belleza de los propios ojos por parte de la pastora amada, etc... (p. 164)

43. No se trata, por supuesto de tomarse al pie de la letra el presunto carácter autobiográfico y testimonial de los textos como lo hacían los críticos que, a inicios del siglo XX, acusaban de insinceridad a los petrarquistas y al propio Petrarca en casos extremos: «But his insincerity can be pushed back even to Petrarch himself. At Arqua, as an old man, he rewrote his poems, altering lines: so that the Canzoniere is rather a work of art than a record of the objective fact.» (John Berdan, «A Definition of Petrarchismo», PMLA 24/4 (1909), pp. 699-710, cit. p. 705). Nadie tendría hoy la ingenuidad de reprochar a un poeta el escribir una obra de arte y no la crónica fidedigna de hechos objetivos. Sin embargo la historia reconstruible tiene que tener cierto grado de verosimilitud, y debe haber cierta concordancia entre la visión retrospectiva de un amor vivido y la formación progresiva de una escritura poética para que el resultado aparezca como un cancionero. En el caso de Cetina, la suposición de esa verosimilitud choca con pruebas textuales de que su poesía acerca de amores juveniles (que probablemente tuvieron alguna forma de existencia) fue en gran parte, y quizás enteramente, forjada a posteriori.

44. Véase Jesús Ponce Cárdenas, "Cauces de la imitación en el Renacimiento: Gutierre de Cetina y Nicolò Franco», art. cit. 
Este hallazgo sugiere que lo que real y verdaderamente Cetina buscaba en sus lecturas poéticas eran las fórmulas expresivas, los motivos eruditos, el lenguaje y la retórica, importándole poco en el fondo el contenido o incluso el colorido emocional del conjunto. Cetina escribe poemas petrarquistas sobre la falsilla de los venenosos y brillantes textos de un notorio y virulento antipetrarquista ${ }^{45}$. Él podía utilizar los materiales hallados en la espléndida poesía italiana, cualquiera que fuera su uso originario, para fines propios, cortesanos, amistosos, galantes o meditativos, o simplemente para ejercicios estilísticos de varia índole. Demuestra que el corpus bucólico dedicado a Dórida no puede ser anterior a 1541 y que no se trata pues de composiciones de la primera juventud, escritas al calor de una pasión casi adolescente por una muchacha sevillana a la que pronto dejaría atrás en favor de otros amores.

Las Rimas de Cetina editadas por Jesús Ponce constituyen a nuestro parecer un hito en el estudio de la poesía espańola del siglo XVI. En ellas tenemos una edición completa, magníficamente presentada y anotada, de un poeta valioso e históricamente fundamental, y una verdadera introducción a la cultura literaria del Renacimiento, que volvemos a descubrir desde el lado hispánico, no mediante generalidades que siempre corren el albur de ser vacuas, sino del modo más concreto, siguiendo los pasos del poeta por diversos puntos de la geografía europea. En este volumen de manejo agradable pese a su grosor, impreso con pulcritud y con bellas ilustraciones, está integrada, al servicio de una lectura atenta, escrupulosa y clarividente, toda la investigación hasta ahora llevada a cabo sobre Cetina. Pero además de cumplir el cometido de hacer practicable y apetecible un poeta del pasado, aprovechando a fondo varias décadas de labor universitaria, esta edición constituye un trabajo de investigación de envergadura, que sintetiza y completa lo hallado sobre la biografía de Cetina, sus fuentes, su oficina poética, el significado de su producción en verso. Hemos tratado de mostrarlo a través de varios ejemplos, pero sin pretender agotar las pruebas, que serían tantas como páginas contiene el volumen. En muchos frentes, Jesús Ponce nos ofrece un Cetina rejuvenecido, a quien podemos leer tal como fue en su tiempo, respondiendo a la multitud de voces que lo rodeaban, pero precisamente por ello, como nuestro contemporáneo, con quien revivimos, como viajeros en el tiempo, lo que fueron la Sevilla, la Espańa, la Europa de los años centrales del siglo XVI.

45. Nicolò Franco es conocido principalmente en la historia de las letras italianas por su diálogo Il Petrarchista, publicado en Venecia en 1539; se trata de una sátira sumamente insolente y desacralizadora que toma por blanco el culto contemporáneo de Petrarca y la práctica poética de sus imitadores. Se le debe además la forja del término "petrarchista». Sobre el antipetrarquismo, cuya existencia niegan algunos (como Amedeo Quondam), puede leerse el ensayo, vindicación de unos personajes que se niegan a plegarse al conformismo ambiente, de Marziano Guglielminetti, "L'antipetrarchismo», Dynamique d'une expansion culturelle. Pétrarque en Europe XIV $V^{\mathrm{e}} X \mathrm{X}^{\mathrm{e}}$ siècle. Actes du XXVI congrès international du CEFI, Turin et Chambéry, 11-15 décembre 1995. Études réunies et publiées par Pierre Blanc, Paris, Champion, 2001, pp. 75-83, que concluye: «Salvare, evitare, far meditare non erano i loro traguardi espressivi: se di riscrittura si tratta, anche per gli antipetrarchisti, si avverta che fu un'operazione sacrilega, antimagistrale». 